\title{
Religious Involvement and Dynamics of Marijuana Use: Initiation, Persistence, and Desistence
}

\author{
Jeffery T. Ulmer \\ The Pennsylvania State University, University Park, Pennsylvania, USA \\ Scott A. Desmond \\ Indiana University Purdue University-Indianapolis, Indianapolis, Indiana, USA \\ Sung Joon Jang and Byron R. Johnson \\ Baylor University, Waco, Texas, USA
}

\begin{abstract}
Studies that examine the effects of adolescent religiosity on the initiation of, persistence in, and desistence from delinquency are rare. Yet, religion may differentially affect dimensions of delinquency in the early life course. Therefore, using data from the National Longitudinal Study of Adolescent Health (Add Health), we examine the relationship between measures of adolescent religion, as well as changes in religious involvement, and later patterns of marijuana use. We also examine the extent to which religious effects, if any, are mediated by key predictors of delinquency drawn from prominent criminological theories. The results suggest that the primary effect of religion on marijuana use is to prevent its initiation in the first place. Only part of religion's preventative effect on initiation is mediated by social bonds, delinquent peers, or self control. Although religious youth are less likely to ever use marijuana, adolescent religious involvement does not significantly predict desistence from marijuana use.
\end{abstract}

Sociologists since Durkheim have recognized that religion is a core element of culture, and that it therefore is a powerful potential motivator of and control on behavior (Smith 2003; see also Vaisey 2009). Religion has powerful but insufficiently understood effects on behavior (Pargament 2008; Pargament et al. 2005). Religion is known to exert both mediated and unmediated effects on motivation, health, coping with distress, and other behaviors (Koenig et al.

Received 13 September 2010; accepted 23 March 2011.

This research uses data from the National Longitudinal Study of Adolescent Health (Add Health), a project designed by J. Richard Udry, Peter S. Bearman, and Kathleen Mullan Harris, and funded by a grant P01-HD31921 from the National Institute of Child Health and Human Development, with cooperative funding from 17 other agencies. Special acknowledgment is due Ronald R. Rindfuss and Barbara Entwisle for assistance in the original design. Persons interested in obtaining data files from Add Health should contact Add Health, Carolina Population Center, 123 W. Franklin Street, Chapel Hill, NC 27516-2524. This research was supported by a grant from the Office of Juvenile Justice and Delinquency Prevention (2006-JF-FX-0072).

Address correspondence to Jeffery T. Ulmer, Ph.D., The Pennsylvania State University, Department of Sociology, 906 Oswald Tower, University Park, PA 16802-6207, USA. E-mail: jtu100@psu.edu 
2001). Adolescent religiosity is inversely related to a variety of delinquent behaviors, including drug use and underage drinking, interpersonal violence, and non-violent crime (for reviews, see Baier and Wright 2001; Benda 1997; Chitwood et al. 2008; Johnson et al. 2000; Regnerus 2006).

Previous research has examined mediators through which religion might have an indirect influence on delinquency and substance use. For example, researchers have examined the effect of religion on moral beliefs, social bonds, exposure to non-delinquent peers, self control, and strain (e.g., Burkett and Warren 1987; Benda and Corwyn 1997; Cochran et al. 1994; Desmond et al. 2007; Jang and Johnson 2003; Johnson et al. 2001; Welch et al. 2006). In addition, religiosity may have unique influences on behavior that are not mediated by non-religious factors (Pargament et al. 2005).

However, scant research exists on religion and changes in delinquent involvement, such as initiation, persistence, and desistence (Petts 2009). If religion is negatively related to overall delinquent involvement, it should protect against the initiation of delinquency. Further, religiosity might differentially affect dimensions of delinquent careers, such as initiation, intermittent involvement, or desistence. Given initial involvement, there are potential reasons to expect religiosity to foster desistence. Once individuals become involved in deviant behavior, a strong religious background, or an increase in religious involvement, might help steer them away from delinquent behavior (Giordano et al. 2008; Petts 2009).

We examine the effect of early adolescent religion, and then later changes in religiosity, on the initiation of, persistence in, and desistence from marijuana use in later adolescence and early adulthood. We examine two sets of questions. First, to what extent do early adolescent religious involvement, belief, and denomination predict the initiation of marijuana use, as compared to persistence, intermittent use, and desistence, net of extra-religious factors identified by leading criminological theories. Second, to what extent do changes in religious involvement from early adolescence to late adolescence/early adulthood affect abstinence, persistence, or desistence, net of the enduring effects of extra-religious theoretical predictors from earlier adolescence?

We focus on marijuana use for four reasons. First, secular and religious institutions both condemn serious crime/delinquency like violence and stealing, but religious institutions are more likely than secular ones to disapprove of things like excessive drinking and illicit drug use (Burkett and White 1974; Cochran and Akers 1989). Second, marijuana use is more prevalent among a variety of youth than more serious forms of delinquency, thus providing greater behavioral variation to analyze. Third, while marijuana use is a less serious form of delinquency, it can place youth at risk for negative sanctions, especially arrest, punishment, and formal labeling, which can limit future opportunities (Jang et al. 2008).

\section{RELIGION AND DYNAMICS OF DELINQUENCY}

We define religiosity, or religious involvement, as the extent of an individual's involvement in organized religion as well as the salience of religion to the individual's everyday life, as indicated by behavioral or perceptual measures (e.g., religious service attendance, frequency of prayer, and perceived importance of religion). Other dimensions of religion of interest include religious denomination and particular religious beliefs. Religious involvement appear to help protect youth from delinquent behavior and other deviant activities, especially drug use and 
underage alcohol use (Chitwood et al. 2008; Johnson et al. 2000). There is also evidence that religious involvement has a cumulative effect throughout adolescence and young adulthood that reduces the risk of later adult drug use (Jang et al. 2008), and religious involvement tends to lower the risks of a broad range of delinquent behaviors, including both minor and serious forms of criminal behavior (Regnerus 2006; Wallace et al. 2007).

Little is known, however, about the processes by which religion might foster desistence from crime and delinquency, and there is almost no theorizing about the issue (Schroeder and Frana 2009). It is reasonable to expect, however, that a background of religious involvement might not only foster abstinence from delinquency and substance use, but might also later encourage desistence if one does become involved (see Petts 2009). A youth might become involved with marijuana for a time, but a background of earlier religious socialization in adolescence might lead the youth to eventually reject marijuana use out of guilt or moral identity dissonance. That is, religious involvement in earlier adolescence might lay a foundation of moral beliefs and moral narratives, and may create a moral identity that is influential over the long term (Smith 2003). Even if a youth experiments with marijuana or uses it for a time (due to peer pressure, strain, rebellion, etc.) his or her earlier religious experience may form a standpoint from which they will eventually reject marijuana use and desist. In addition, change in religiosity might be related to persistence or desistence. In particular, an increase in religious involvement might foster desistence from marijuana use (Petts 2009). A decrease in religiosity might release individuals from the hold of religious beliefs forbidding marijuana use, and free them to initiate use in later adolescence or early adulthood (Petts 2009).

The opportunity to bounce back from a mistake is a central message often communicated within various religious traditions. Indeed, the concepts of redemption and forgiveness might be viewed as precursors or antecedents potentially reinforcing desistance. Religion may provide a mechanism enabling a person who has experienced a lapse of self control or adherence to his or her own moral standards, for example, to pursue a second chance, and desist.

In addition, religion in particular may influence desistence from marijuana use given that religion is "a search for significance in ways related to the sacred" (Pargament 1997:32). When religion leads one to perceive a violation of their beliefs about the sacred in their own behaviors or lifestyles, such as drug use, whether casual or addictive, it may result in a transformative event that triggers a termination of drug use. In this way religion might be viewed as a "turning point" or "hook for change" that explains discontinuity in deviance (Giordano et al. 2008).

Though scholars have examined religiosity and overall participation in crime and delinquency, there are few studies of how religiosity affects dynamics of delinquency, such as abstinence vs. initiation and persistence vs. desistence. We know of only three studies that explicitly focus on religiosity (or spirituality) and desistence. Chu (2007) found that frequency of church attendance was associated with desistence from marijuana and other drug use, and religious salience was negatively related to the onset of drug use, in analyses of Waves 5-7 of the National Youth Survey. Like most studies, however, Chu's (2007) study utilized limited measures of religiosity, with single items measuring religious behavior (church attendance) and religious salience (perceived importance of religion). In addition, Chu's (2007) analysis included few controls for other theoretically important predictors of delinquency and desistence, such as conventional social bonding, peer influence, self control, and strain.

Giordano et al. (2008) examined the effects of religiosity (measured as church attendance and "spirituality," a measure of self-reported "closeness to God") on desistence using quantitative 
and qualitative interview data from a sample of socioeconomically disadvantaged offenders. Their quantitative analysis showed no significant effect of religion on the likelihood of sustained desistence. Their qualitative data, however, did point to several possibilities in religion's role in fostering desistence from crime. The interviews showed that religion was a potential "hook" for life course change away from crime in the following ways: 1) religion was structurally and subjectively available as a source of "prosocial capital," 2) religion was associated with positive emotions and a resource for coping with negative emotions, and 3) religion potentially fostered or strengthened ties to prosocial others. However, religion, by itself, was sometimes unable to overcome or offset other criminogenic factors in the offenders' highly disadvantaged environments.

Third, Schroeder and Frana (2009), using qualitative interview data, investigated ways men in a halfway house used religion as an emotional coping mechanism in attempting to desist from substance abuse and other deviance. They found men used religion as a form of emotional comfort, a distraction from stress, and a marker of personal change. Finally, although not focused on desistence per se, Petts (2009) found that adolescent religious involvement, and increases in such involvement, predicted lower levels of delinquency in adolescence and early adulthood.

The aforementioned studies imply religion may foster abstinence from delinquency, such as marijuana use, and a religious background might at least partially foster desistence from delinquency later, if adolescents do become initially involved. Giordano et al. (2008), Petts (2009), and Schroeder and Frana (2009) in particular imply that increases in religious involvement might also foster desistence and discourage persistence. However, key theories in criminology imply that religious influence on delinquency would be either in part or wholly mediated by factors such as peer influence, prosocial bonds, self control, and strain.

\section{Intervening Factors: Peer Influence, Conventional Bonds, Self Control, and Strain}

One of the strongest predictors of delinquency is the influence of delinquent peers (for reviews, see Akers 1998; Warr 2002). Religiosity may increase the likelihood that youth will associate with and be influenced by conventionally oriented peers and mentors (Glanville et al. 2008), and decrease the likelihood of being influenced by peers with deviant beliefs, attitudes, and values (see, e.g., Burkett and Warren 1987; Johnson et al. 2001). Likewise, Warr (2002) empirically demonstrated how life-course transitions involving changes in peer relations contribute to desistence from delinquency and crime. If religiosity partly affects delinquency by affecting peer relations in earlier adolescence, we would expect part of religion's effect on the initiation of marijuana use, as well as its later persistence, to be mediated by association with delinquent peers (Benda and Corwyn 1997).

Social control theory argues the strength of one's attachments, commitments, involvements, and moral beliefs discourage deviant behavior (Hirschi 1969). Sampson and Laub's (1993) life course theory of age-graded social bonds also implies that social bonds at one life course stage shape deviant and conventional choices and behavior at later stages. Adolescent religiosity likely fosters prosocial bonds to family, school, community, and voluntary associations, all of which can prevent delinquency (Benda and Corwyn 1997; Cochran et al. 1994; Petts 2009). Religion and spirituality likely inculcate moral beliefs favoring prosocial behavior and discourage 
delinquency. Giordano et al. (2002) also find that prosocial bonds are potential "hooks for change" that foster desistence. We expect that effects of religiosity on dynamics of marijuana use will be partially mediated by earlier adolescent social bonds (Elifson et al. 1983).

Part of religiosity's effect in preventing delinquency onset, discouraging persistence, and encouraging desistence might be mediated by self control. Self control has also long been identified as an important influence on crime and deviance (see review by Hay and Forrest 2006). Lattimore and colleagues (2006) speculate that a key source of self control might be moral messages from caregivers and others. The "muscle" or "strength" model of self control (Muraven and Baumeister 2000) argues that self control is a cognitive resource that is temporarily depleted when it is exercised, just as a muscle is temporarily fatigued with use. Drawing from this "muscle" model of self control, Geyer and Baumeister (2005:418) argue "Religious organizations, as an external source of discipline, can be very helpful to people's personal self control endeavors." At least one previous study suggests that religious individuals exhibit greater levels of self control (Aziz and Rehman 1996). Thus, at least part of religion's influence on delinquency may be mediated by self control, if religious involvement augments the development of greater self control in and before adolescence.

It is also plausible that part of religion's effect on the initiation or desistence in delinquency might be due to religious youth coping differently with strain, which is a risk factor for crime and delinquency (Agnew 2006). Recent evidence suggests that religion might insulate youth from negative emotionality connected to strain, and discourage antisocial strategies for coping with strain (Jang and Johnson 2003; 2005; Wills et al. 2003). Thus, negative emotionality connected to strain in adolescence may mediate any effect that measures of religion have on delinquency.

\section{Unique Effects of Religion}

However, religiosity may exert unique influences that are not mediated by the non-religious predictors noted earlier (Johnson et al. 2001; Pargament et al. 2005). Prior research finds direct effects of religiosity on delinquency and drug use net of the influence of peers, social bonds, self control, or strain (e.g., Benda 1997; Jang and Johnson 2003; 2005; Johnson et al. 2001; Welch et al. 2006). We therefore expect that at least a portion of religiosity's influence on behavior will be unique rather than mediated by other variables. According to Pargament (2008, p. 32), " . . . the sacred is more than a source of solutions and problems, it is a distinctive source of significance.' In addition, Smith (2003) argues that religion provides individuals with distinctive moral narratives and cultural meanings that guide behavior. Pargament et al. (2005) review sociological and psychological research on the effects of religion on motivation, meaning, health, coping, and distress, and conclude that religious and spiritual experiences and beliefs are unique causal influences on these domains of life. "Religion may be a unique aspect of human functioning, one that cannot simply be reduced to or explained away by presumably more basic psychological, social, or physical processes" (Pargament et al. 2005:680). Religion, and personal religiosity in particular, likely entails complex processes of socialization and identity formation, and their effects on youth behavior may not be reducible to the effects of peer influence, social bonds, self control, or shaping how individuals experience strain. Thus, religion might exhibit effects on marijuana use that are not fully mediated by these predictors from general theories of delinquency. 


\section{The Present Study}

Chu (2007, p. 677) stated that her study provided “ . . . a starting point for exploring the relationship between religiosity and desistence from drug use." Our study extends Chu's, Giordano et al.'s (2008), and Schroeder and Frana's (2009) in several important ways. First, we use more extensive measures of religion than either Chu (2007) or Giordano et al. (2008), both of which by necessity were limited to relying on only measures of church attendance and salience of religion. Compared to Chu's (2007) study, we also include more measures of other important predictors of delinquency, such as peer influence, conventional social bonding, self control, and negative emotions. Furthermore, the data we use allow us to control for parental religiosity, which is an important influence on youth religiosity and a potentially confounding factor, while Chu (2007) did not control for parental religiosity. We also extend Giordano et al. (2008) by using data from a nationally representative survey of youth, rather than a sample of disadvantaged offenders. Finally, we answer Schroeder and Frana's (2009) call for broader work that examines the role of religious factors in initiation of and desistence from deviance.

We expect religious involvement during earlier adolescence to reduce the probability of initiating drug use later. We also expect that a background of religious involvement in earlier adolescence might also later encourage desistence from marijuana use if one does become involved. If religiosity in earlier adolescence lays a foundation of moral beliefs and narratives exerting long term influence (Smith 2003), then those with a background of greater religious involvement should be more likely to abstain from marijuana. If they do use, they would be more likely to do so on experimentally and then desist, since such behavior would not be congruent with their earlier foundation of moral socialization and moral narrative. Similarly, those whose religious involvement increases over time might be expected to eschew behavior such as marijuana use that might not be in line with their newer religious socialization, while those whose religious involvement decreases might be more likely to initiate or persist in marijuana use, since they would be freed from the internal and external restrictions of religion against such deviance. We thus test the following hypotheses:

$\mathbf{H}_{\mathbf{1}}$ Religiosity will be associated with a decreased likelihood of initiating marijuana use.

$\mathbf{H}_{2}$ Religiosity will be associated with greater odds of desistence from marijuana use, given initiation.

$\mathbf{H}_{3}$ The effects of religiosity on the dynamics of marijuana use will be partially mediated by peer associations, prosocial bonds, self control, and strain. However, religious involvement will have independent, unique effects net of these other sets of predictors.

$\mathbf{H}_{4}$ Increased religiosity from adolescence to young adulthood will be associated with an increased likelihood of desistence, given earlier marijuana use. Decreased religious involvement will be associated with increased odds of later initiation, and decreased odds of desistence.

\section{DATA AND METHODS}

We used data from the National Longitudinal Study of Adolescent Health (Add Health). For Add Health, a cluster sampling design with systematic sampling methods and implicit stratification was used to select a representative sample of 80 high schools, along with 52 "feeder schools" (i.e., junior high/middle schools) for those high schools that did not span grades 7 through 12. A nationally representative "core sample" of 12,105 7th through 12th graders and "special oversamples" of 15,454 adolescents (e.g., ethnic minorities and students with 
physical disabilities) were drawn from school rosters. Of these, 20,745 students were interviewed mostly at home between April and December 1995. For each adolescent respondent a parent was also interviewed at Wave I $(n=17,700)$. Interviews at Wave II were conducted with 14,738 adolescents from April through August 1996. Wave III data were collected five years later. After attrition between waves and listwise deletion of cases with missing data, the total number of cases for our analysis is 7,331 (for a complete description of the Add Health Data, see Bearman et al. 1997). ${ }^{1}$ We adjusted for the effects of non-response across waves, unequal probability of selection, and clustering of students within schools using the STATA's survey commands (Chantala and Tabor 1999). We also used Wave 1 parent data for parent's religiosity and whether the parent received public assistance.

\section{Dependent Variables: Patterns of Marijuana Use}

In order to establish the appropriate temporal order between independent and dependent variables, all of the predictor variables are taken from the first wave In-Home survey completed by the adolescents and the parent survey (except for the change in religious involvement measures, which use data from all three waves), while the dependent variable is constructed using the first, second, and third waves of the survey. Our dependent variable captures the initiation of marijuana use, unstable/intermittent use, desistence, and persistence from Wave 1 to Wave 3 of the Add Health study. The dependent variable is coded $0=$ never used, $1=$ initiation, $2=$ unstable/intermittent, $3=$ desistence, and $4=$ persistence. At each wave of Add Health, adolescents were asked if they had used marijuana in the last year or if they had used marijuana since the last wave of the survey. Adolescents who did not use marijuana at Wave 1, Wave 2, or Wave 3 were classified as never using marijuana. Conversely, persistent users used marijuana across all three waves.

The initiation category included individuals who did not use marijuana at Wave 1, but did use at Wave 2 and Wave 3. Adolescents who did not use marijuana at Wave 1 or Wave 2, but did use at Wave 3 were also included in the initiation category. Thus, anyone who initiated use between Waves 1 and 2 or Waves 2 and 3 were categorized as initiators. Unstable or intermittent users smoked marijuana at Wave 1, did not use marijuana at Wave 2, and used marijuana again at Wave 3.

Adolescents who used marijuana at Wave 1, but did not use marijuana at Wave 2 and did not use marijuana at Wave 3 were placed in the desistence category, as were those who used marijuana at Wave 1 and Wave 2, but did not use at Wave 3. Similar to initiation, the first group represents adolescents who desisted from marijuana use between Waves 1 and 2, while the second group represents adolescents who desisted between Waves 2 and 3. Adolescents who did not use marijuana at Wave 1, used marijuana at Wave 2 one year later, but did not use marijuana at Wave 3 five years later were also placed in the desistence category. In supplemental analyses, we replicated our models with different categorizations of our dependent variable where we included those who did not use at Wave 1, used at Wave 2, and stopped using

\footnotetext{
${ }^{1}$ The vast majority of adolescents who were seniors in high school at Wave 1 were not re-interviewed at Wave 2. In addition, 4,783 adolescents who were eligible for Wave 3 were not interviewed again because they could not be located or were unable to be interviewed again. Analysis of non-response suggests that sample attrition introduces very little bias in estimates of marijuana use (less than half a percent), which we use for our dependent variable (Chantala et al. 2004
} 
at Wave 3 in the "intermittent" category. The results did not differ substantially from those presented.

\section{Religion}

Adolescents' religious involvement was operationalized as the frequency of religious service attendance, perceived importance of religion, and frequency of prayer. Each of these three aspects of religious involvement was measured with a 4-point Likert scale (0 to 3). We summed scores on the three items to construct a composite measure $(\alpha=.875)$, which ranges from 0 to 9 with higher scores indicating greater religiosity. Parents were asked the same three questions, so parents' religious involvement was constructed in the same way $(\alpha=.832)$.

We constructed a measure of religious denomination based on adolescents' responses to a question about their religious affiliation, which were then grouped into a series of dummy variables using the Steensland et al. (2000) RELTRAD classification scheme. While the RELTRAD scheme includes seven categories, we combined Jewish youth with the "other" (e.g., Mormon, Jehovah's Witness, Muslim, Hindu, and Unitarian) category because there were few Jewish adolescents in the Add Health sample. Our six categories are mainline Protestant, evangelical Protestant, black Protestant, Catholic, other affiliation, and no religion, with no religion being used as the reference category in our analysis. Besides this denominational measure, adolescents were asked whether they thought of themselves as born again Christians $(0=$ no, $1=$ yes $)$ and whether they agreed $(=1)$ or disagreed $(=0)$ that the sacred scriptures of their religion were the word of God and completely without any mistakes (religious literalism).

\section{Mediating Variables}

First, parental attachment was measured using five items asking about adolescents' relationships with their parents in terms of affective ties, close communication, and general satisfaction with the relationship. Since the same items were repeated for mothers and fathers, we first constructed two subscales, attachment to mother $(\alpha=.941)$ and attachment to father $(\alpha=.980)$, before averaging the subscales to form a single measure of attachment to parents. Second, school attachment was measured using five items about adolescents' sense of belonging to school, as well as positive feelings toward school, teachers, and other people at school $(\alpha=.761)$.

To measure delinquent peers, an important dimension of social learning theory (Akers 1998), we employed an item asking youth how many of their "three best friends" used marijuana at least once a month $(0=$ no friends, $1=$ one friend, $2=$ two friends, $3=$ three friends). We also constructed a measure of negative emotions, a key concept from Agnew's (2006) general strain theory. We used nine items asking youth about their experiences with depression and anxiety $(\alpha=.83)$.

We constructed an 11-item index of self control $(\alpha=.71)$. First, we used the same five items used by Perrone and colleagues (2004), who also utilized the Add Health data to study self control. Adolescents were asked how often they had difficulty getting along with their teachers, paying attention in school, and getting homework done. Perrone et al. (2004) argue these items capture the temper, impulsivity, and preference for physical tasks dimensions of self control. Adolescents were also asked how often they had trouble keeping their minds on what they were 
doing. The last item, which Perrone et al. (2004) suggest indicates how self-centered an adolescent is, asked adolescents to indicate their level of agreement with the statement "You feel you are doing everything just about right."

In addition to the items used by Perrone et al. (2004), we added six items related to how adolescents make decisions and solve problems (e.g., "When making decisions, you usually go with your gut feeling without thinking too much about the consequences of each alternative"'), since lack of care in decision making and impulsivity are said to be components of low self control. These items also suggest a lack of consideration for the long-term implications of behavior, a preference for simple and immediate problem resolution, and a tendency to be physical rather than mental.

While we examined change in religious involvement across waves, unfortunately we could not examine the effects of changes in delinquent peers, social bonds, strain, and self control. This is because the third wave of Add Health either did not contain sufficiently comparable items for these measures relative to Wave 1 , or else did not contain relevant measures of all items.

\section{Control Variables}

We also included sociodemographic control variables. Included in our model are: adolescents' sex $(0=$ female, $1=$ male), age (computed by subtracting the interview date from the adolescent's date of birth), race (for which four dummy variables were constructed for African American, Asian, other race, and white, with white as the reference category), ethnicity $(0=$ non-Hispanic, $1=$ Hispanic $)$, intact family $(0=$ not living with both biological parents, $1=$ living with both biological parents), and two measures of social class, parents' education and welfare status. Parents' education was based on the adolescents' reports of how far their parents went in school. When both parents were present, parents' education reflects the parent with the highest level of education, whereas, for single-parent families, it is the level of education for the parent who was present in the home. Welfare status was measured using an item asking whether parents or any other member of their household received some form of public assistance $(0=$ did not receive public assistance, $1=$ received welfare). Finally, we included a measure of adolescents' academic performance, specifically, their grades in four subjects: English or language arts, math, history or social studies, and science. Each grade received during "the most recent grading period" was reported as “A," "B,', “C,', or "D or lower," which were coded $4,3,2$, and 1 , respectively, to compute a grade point average $(\alpha=.982)$.

\section{Analytic Strategy}

Given that our dependent variable represents nominal categories that cannot be ordered, we used multinomial logistic regression (Long 1997). A multinomial logistic regression "can be thought of as simultaneously estimating binary logits for all possible comparisons among the outcome categories" (Long 1997:149). First, we focused on how religiosity influences the different patterns of marijuana use by comparing never use versus initiation, never use versus persistence, and intermittent use versus persistence. Second, in order to determine the effects of religiosity on desistence, we compared never use versus desistence, intermittent use versus desistence, and persistence versus desistence. Finally, for comparisons that revealed a significant effect 
for adolescent religiosity, we conducted a fuller analysis to determine if the effect of religiosity was mediated by social bonds, social learning, self control, and/or negative emotions.

\section{RESULTS}

We first briefly present descriptive statistics for our independent and dependent variables, and then summarize results from multinomial regression models showing various comparisons between the categories of never using, initiation, intermittent use, desistence, and persistence. Full descriptive statistics are available from the authors on request. Of particular interest is the distribution of marijuana use patterns among the youth. About $47 \%$ never used marijuana, while about $21 \%$ initiated use at some point between Wave 1 and Wave 3 . About $5 \%$ of the sample displayed an intermittent or unstable pattern of use and $22 \%$ used at some point and then desisted. Only $6 \%$ of the adolescents persistently used marijuana across all three waves. ${ }^{2}$

\section{Initial Marijuana Use}

Table 1 depicts the results for a series of multinomial logistic regressions focusing on initial marijuana use.

The first column of Panel A in Table 1 shows the results for adolescents who never used marijuana compared to adolescents who initiated marijuana use at Wave 2 or 3. Religious youth are moderately more likely to never use marijuana than to initiate use. A one standard deviation (3.15) difference in religious involvement would be associated with an almost $19 \%$ difference in the odds of initiating marijuana use. In other words, youth with a score of 9 for religious involvement would have $19 \%$ lesser odds of initiating marijuana use than those youth with a score at the mean of 5.84. Interestingly, the results suggest Catholics, compared to those with no religious affiliation, are significantly more likely to initiate marijuana use than to never use. Mainline Protestants and adolescents with "other" religious affiliations are also more likely to initiate marijuana use than to never use, compared to adolescents with no religious affiliation.

The second column (Panel A) of Table 1 depicts the results for adolescents who never used marijuana compared to adolescents who were persistent marijuana users. Similar to the results for never use versus initiation, the results for never use versus persistence suggest Catholics and mainline Protestants, compared to adolescents with no religious affiliation, are significantly more likely to be persistent marijuana users than to never use marijuana. In contrast, adolescents who believe in a literal interpretation of the sacred scriptures of their religion are less likely to be persistent marijuana users. Adolescent religious involvement also significantly decreases the likelihood of persistent use. A one standard deviation difference in religious involvement is associated with a $30 \%$ difference in adolescents' odds of persistent use.

\footnotetext{
${ }^{2}$ There are more desisters than there are initiators. This counterintuitive feature is due to the fact that many individuals began using marijuana sometime before Wave 1. Based on a question (from the first in-home survey) that asks about age at first marijuana use ("How old were you when you tried marijuana for the first time?'), we know that adolescents who use marijuana typically begin using around age 15 (the median age of first marijuana use is 14, while the modal age is 15). At Wave 1, adolescents in the sample are between 11 and 21 years of age. Therefore, many of the adolescents who use marijuana started using before Wave 1. Over time (Waves 2 and 3), some of these individuals (125 in this analysis) are later classified as desisters, while others were unstable and/or persistent users.
} 
TABLE 1

Multinomial Logistic Regression for Initial Use of Marijuana (Mediating Variables and Controls Included but Not Shown)

\begin{tabular}{lccc}
\hline Panel A & $\begin{array}{c}\text { Never use (contrast) vs. } \\
\text { initiation }\end{array}$ & $\begin{array}{c}\text { Never use (contrast) vs. } \\
\text { persistence }\end{array}$ & $\begin{array}{c}\text { Intermittent (contrast) vs. } \\
\text { persistence }\end{array}$ \\
\hline Catholic & $.986(.217)^{* *}$ & $.820(.365)^{*}$ & $.283(.439)$ \\
Evangelical Protestant & $.476(.246)$ & $.510(.393)$ & $.383(.465)$ \\
Black Protestant & $.593(.319)$ & $.846(.592)$ & $-.172(.800)$ \\
Mainline Protestant & $.667(.236)^{* *}$ & $.763(.330)^{*}$ & $.516(.465)$ \\
Other Affiliation & $.597(.248)^{*}$ & $.779(.398)$ & $.335(.462)$ \\
Religious Literalism & $-.107(.116)$ & $-.442(.203)^{*}$ & $-.129(.224)$ \\
Born Again Christian & $.101(.114)$ & $-.159(.214)$ & $-.083(.267)$ \\
Parent Religious Involvement & $-.042(.022)$ & $-.040(.031)$ & $-.003(.032)$ \\
Adolescent Religious Involvement & $-.060(.023)^{*}$ & $-.101(.039)^{*}$ & $-.047(.047)$ \\
\hline & Never & use (contrast) vs. & Intermittent $($ contrast) vs. \\
Panel B & desistence & Persistence $($ contrast $)$ vs. \\
\hline Catholic & $.196(.224)$ & $-.341(.380)$ & desistence \\
Evangelical Protestant & $.258(.218)$ & $.132(.401)$ & $-.624(.297)^{*}$ \\
Black Protestant & $.298(.276)$ & $-.720(.729)$ & $-.251(.360)$ \\
Mainline Protestant & $.147(.220)$ & $-.100(.434)$ & $-.548(.543)$ \\
Other Affiliation & $.311(.221)$ & $-.133(.414)$ & $-.616(.288)^{*}$ \\
Religious Literalism & $-.023(.146)$ & $.290(.216)$ & $-.468(.362)$ \\
Born Again Christian & $-.185(.126)$ & $-.109(.206)$ & $.420(.196)^{*}$ \\
Parent Religious Involvement & $-.011(.022)$ & $.026(.033)$ & $-.026(.229)$ \\
Adolescent Religious Involvement & $-.052(.028)$ & $.029(.040)$ & $.049(.035)$ \\
\hline
\end{tabular}

${ }^{*} p<.05 ;{ }^{* *} p<.01 . \mathrm{N}=7,331$. Standard Errors are in parentheses.

The third column in the top of Table 1 compares unstable or intermittent use with persistent use. In this comparison, none of the denominational variables affect the likelihood of unstable versus persistent use. Furthermore, religious literalism, being a born again Christian, parents' religious involvement, and adolescents' religious involvement do not significantly differentiate unstable versus persistent marijuana use either. In fact, the only variable that significantly predicts persistent versus unstable marijuana use is delinquent peers. Adolescents with more marijuana using peers are more likely to be persistent marijuana users and less likely to be intermittent marijuana users.

\section{Desistence from Marijuana Use}

Panel B of Table 1 depicts the results for a series of multinomial logistic regressions focusing on desistence from marijuana use compared with other patterns. The first column of Panel B shows the results for adolescents who never used marijuana compared to adolescents who desisted from marijuana use. The results suggest religious involvement does not have a significant effect on never using marijuana versus desistence from marijuana use. There are no denominational 
differences for this comparison, and religious literalism, status as a born again Christian, parents' religious involvement, and adolescents' religiosity do not differentiate those who never used marijuana from those who used and then desisted from marijuana use.

The second column in Panel B depicts the results for adolescents who were unstable or intermittent marijuana users versus those who desisted. Similar to the results for never used versus desistence, there are no significant effects for religious affiliation. More importantly, after controlling for theoretically important variables, religious involvement does not have a significant effect when unstable marijuana users are compared to adolescents who desisted from marijuana use, nor do religious literalism, being a born again Christian, or parents' religious involvement.

The third column in Panel B shows the results from comparing persistent marijuana users with those who desisted from marijuana use. Similar to previous results, Catholics and mainline Protestants, compared to youth with no religious affiliation, are substantially more likely to be persistent marijuana users than to use marijuana and then desist. Catholics' desistence odds are $46 \%$ less than those of youth with no affiliation, and mainline Protestants' desistence odds are comparable to those of Catholics. Youth who believe in a literal interpretation of the sacred scriptures of their religion are more likely to desist from marijuana use (given initial use) than to persist. Adolescent religious involvement does not significantly differentiate persistence from desistence.

\section{Intervening Factors}

In order to gain a better understanding of the theoretical mechanisms that mediate the effect of adolescent religiosity on marijuana use, Table 2 presents a series of regression models, each with an intervening variable(s) drawn from leading theories of delinquency. Since religiosity's major effect seems to be in preventing youth from using marijuana at all (and thus, by implication, persistent marijuana use), we focus on the comparison of never using versus initiation.

Model 1 only contains the measures of religiosity and the control variables. For model 2, we added two social bonding measures, parental attachment and school attachment. Adding the social bonding variables to the model decreases the effect of adolescents' religious involvement by $13.4 \%$ (from -.082 to $-.071 /-.082$ ). ${ }^{3}$ For model 3 , we added a key variable drawn from social learning theory, associating with delinquent peers. Adding delinquent peers to the model decreases the effect of adolescents' religious involvement by $11.0 \%$ (from -.082 to -.073 ). Similar to the results for the social bonding measures, including self control (model 4) also reduces the effect of adolescents' religious involvement by $13.4 \%$. Finally, when negative emotions are included in the model (model 5), the effect of religious involvement is unchanged,

\footnotetext{
${ }^{3}$ The indirect effect of adolescent religious involvement on marijuana use can be determined by subtracting the effect of adolescent religious involvement on marijuana use when the mediator is included in the model (model 2) from the effect of adolescent religious involvement on marijuana use when the mediator is not included in the model (model 1). Therefore, the indirect effect of adolescent religious involvement on marijuana use is from -.082 to $-.071=$ -.011 . We are not aware of any method that can be used to determine if the indirect effects in a multinomial logistic regression are statistically significant (but see footnote 5 for supplemental analysis using ordinary least squares [OLS]). Dividing the indirect effect $(-.011)$ by the total effect $(-.082)$, however, yields the percentage of the total effect that is mediated or indirect. This provides an indication of the effect size (i.e., the larger the percentage, the larger the indirect effect).
} 
TABLE 2

Multinomial Logistic Regression for Never Used Versus Initiation (Standard Errors)

\begin{tabular}{|c|c|c|c|c|c|c|}
\hline & Model 1 & Model 2 & Model 3 & Model 4 & Model 5 & Model 6 \\
\hline Catholic & $1.066(.215)^{* *}$ & $1.032(.216)^{* *}$ & $1.037(.212)^{* *}$ & $1.020(.215)^{* *}$ & $1.061(.213)^{* *}$ & $.986(.217)^{* *}$ \\
\hline Evangelical Protestant & $.621(.256)^{*}$ & $.565(.252)^{*}$ & $.569(.249)^{*}$ & $.537(.254)^{*}$ & $.621(.254)^{*}$ & $.476(.246)$ \\
\hline Black Protestant & $.779(.307)^{*}$ & $.701(.303)^{*}$ & $.681(.317)^{*}$ & $.737(.316)^{*}$ & $.775(.306)^{*}$ & $.593(.319)$ \\
\hline Mainline Protestant & $.807(.238)^{* *}$ & $.756(.240)^{* *}$ & $.756(.234)^{* *}$ & $.730(.238)^{* *}$ & $.804(.237)^{* *}$ & $.667(.236)^{* *}$ \\
\hline Other Affiliation & $.712(.249)^{* *}$ & $.641(.249)^{*}$ & $.706(.246)^{* *}$ & $.614(.248)^{*}$ & $.713(.248)^{* *}$ & $.597(.248)^{*}$ \\
\hline Biblical Literalism & $-.198(.111)$ & $-.157(.113)$ & $-.165(.114)$ & $-.150(.113)$ & $-.192(.110)$ & $-.107(.116)$ \\
\hline Born Again Christian & $.058(.113)$ & $.057(.113)$ & $.087(.112)$ & $.059(.117)$ & $.055(.113)$ & $.101(.114)$ \\
\hline $\begin{array}{l}\text { Parent Religious } \\
\text { Involvement }\end{array}$ & $-.027(.021)$ & $-.031(.021)$ & $-.032(.022)$ & $-.036(.021)$ & $-.026(.021)$ & $-.042(.022)$ \\
\hline $\begin{array}{l}\text { Adolescent Religious } \\
\text { Involvement }\end{array}$ & $-.082(.024)^{* *}$ & $-.071(.024)^{* *}$ & $-.073(.023)^{* *}$ & $-.071(.024)^{* *}$ & $-.082(.024)^{* *}$ & $-.060(.023)^{*}$ \\
\hline Sex & $.490(.081)^{* *}$ & $.548(.083)^{* *}$ & $.510(.079)^{* *}$ & $.500(.081)^{* *}$ & $.507(.083)^{* *}$ & $.528(.082)^{* *}$ \\
\hline Age & $-.276(.029)^{* *}$ & $-.297(.029)^{* *}$ & $-.282(.030)^{* *}$ & $-.264(.029)^{* *}$ & $-.279(.029)^{* *}$ & $-.279(.031)^{* *}$ \\
\hline Black & $-.418(.203)^{*}$ & $-.392(.203)$ & $-.411(.217)$ & $-.379(.211)$ & $-.425(.202)^{*}$ & $-.325(.215)$ \\
\hline Asian & $-.795(.192)^{* *}$ & $-.833(.190)^{* *}$ & $-.811(.193)^{* *}$ & $-.766(.189)^{* *}$ & $-.815(.193)^{* *}$ & $-.779(.191)^{* *}$ \\
\hline Other Race & $-.078(.211)$ & $-.098(.208)$ & $-.135(.207)$ & $-.070(.214)$ & $-.080(.210)$ & $-.106(.207)$ \\
\hline Hispanic & $-.358(.147)^{*}$ & $-.369(.147)^{*}$ & $-.356(.145)^{*}$ & $-.335(.144)^{*}$ & $-.360(.147)^{*}$ & $-.336(.141)^{*}$ \\
\hline Biological Family & $-.036(.091)$ & $-.025(.091)$ & $-.028(.091)$ & $-.045(.092)$ & $-.033(.091)$ & $-.032(.092)$ \\
\hline Welfare & $-.328(.128)^{*}$ & $-.310(.129)^{*}$ & $-.334(.128)^{*}$ & $-.327(.126)^{*}$ & $-.330(.127)^{*}$ & $-.312(.126)^{*}$ \\
\hline Parent Education & $.082(.022)^{* *}$ & $.083(.022)^{* *}$ & $.085(.022)^{* *}$ & $.079(.022)^{* *}$ & $.083(.023)^{* *}$ & $.081(.022)^{* *}$ \\
\hline Grades & $-.254(.047)^{* *}$ & $-.208(.050)^{* *}$ & $-.220(.049)^{* *}$ & $-.121(.051)^{*}$ & $-.244(.048)^{* *}$ & $-.093(.054)$ \\
\hline Parent Attachment & & $-.063(.016)^{* *}$ & & & & $-.042(.018)^{*}$ \\
\hline School Attachment & & $-.026(.013)$ & & & & $-.007(.014)$ \\
\hline Delinquent Peers & & & $.343(.072)^{* *}$ & & & $.299(.075)^{* *}$ \\
\hline Self Control & & & & $-.062(.008)^{* *}$ & & $-.057(.010)^{* *}$ \\
\hline Negative Emotions & & & & & $.014(.012)$ & $-.023(.015)$ \\
\hline
\end{tabular}

${ }^{*} p<.05 ;{ }^{* *} p<.01 . \mathrm{N}=7,331$.

indicating that none of the effect of religiosity on marijuana use is attributable to religiosity's effect, if any, on reducing negative emotions.

In sum, rather than initiating marijuana use, religious youth are more likely to never use marijuana. Not surprisingly, religious youth are also therefore less likely to engage in persistent marijuana use. Furthermore, it appears the effect of adolescent religious involvement is mediated roughly equally by social bonds, delinquent peers, and self control, but none of the effect of adolescent religious involvement is mediated by negative emotions. Collectively (model 6), approximately $27 \%$ of the effect of adolescent religious involvement is mediated by social bonding, social learning, and self control. Almost three fourths of the effect of religious involvement is "unique" in that it is not attributable to mediation by these general predictors of delinquency.

As with the results for never use versus initiation, we also conducted supplementary analyses of the theoretical mechanisms that mediate the effect of religiosity on the comparison of never using versus persistent use (results not shown). Similar to the results for the comparison of never use and initiation, part of the effect of adolescents' religious involvement is mediated by social bonding, associating with delinquent peers, and self control. Including parental attachment and school attachment in the model reduces the effect of religious involvement by $16.5 \%$, delinquent 
peers by $21.2 \%$, and self control by $21.2 \%$. In contrast, negative emotions do not mediate any of the effect of adolescents' religious involvement. Combined, approximately $41 \%$ of the effect of adolescents' religious involvement is mediated by social bonding, social learning, and self control, and about $59 \%$ of religious involvement's effects are "unique."

In addition to adolescents' religious involvement, adolescents who believe in a literal interpretation of religious scriptures are also more likely to never use marijuana than to persist. Part of the effect of religious literalism is mediated by social bonding, associating with delinquent peers, self control, and negative emotions. Including parental and school attachment in the model reduces the effect of religious literalism by $16.1 \%$, delinquent peers by $20.4 \%$, self control by $16.0 \%$, and negative emotions by $6.6 \%$. Together, approximately $35 \%$ of the effect of religious literalism is mediated by social bonds, social learning, self control, and negative emotions.

Unlike the analysis for initial marijuana use, adolescents' religious involvement does not have a significant effect on any of the desistence comparisons. Adolescents who believe in a literal interpretation of the sacred scriptures of their religion, however, are more likely to desist from marijuana use than to persist (see Panel B, Table 1). Supplemental analysis of the theoretical mechanisms that mediate the effect of religious literalism on desistence from marijuana use (not shown) indicate that including parental attachment and school attachment reduces the effect of religious literalism by $8.7 \%$, delinquent peers by $13.1 \%$, self control by $9.9 \%$, and negative emotions by $4.2 \%$. Combined, approximately $17 \%$ of the effect of religious literalism is mediated by social bonding, social learning, self control, and negative emotions. ${ }^{4}$

\section{Change in Religiosity}

Does increased religiosity from earlier adolescence lead to desistence from marijuana use or other delinquency in later adolescence or early adulthood? We examine the effect of changes in adolescents' religious involvement from Wave 1 to Wave 3 on patterns of marijuana use. Unfortunately, the three items we used to measure adolescent religious involvement - church attendance, importance of religion, and frequency of prayer-were changed from Add Health Wave 1 to Wave 3. For example, at Wave 1 church attendance was measured on a four point scale, but was measured on a seven point scale at Wave 3, and the response categories for importance of religion were also changed. We addressed this difficulty by attempting to make the Wave 1 and 3 religiosity measures as comparable as possible. At Wave 1, church attendance was measured on a four point scale: $0=$ never, $1=$ less than once a month, $2=$ once a month or more, but less than once a week, and $3=$ once a week or more. At Wave 3, church attendance was measured on a seven point scale: $0=$ never, $1=\mathrm{a}$ few times, $2=$ several times, $3=$ once a month, $4=2$ to 3 times a month, $5=$ once a week, and $6=$ more than once a week. We therefore

\footnotetext{
${ }^{4}$ We conducted supplemental analysis using a measure of frequency of marijuana use. Adolescent religious involvement was significantly related to frequency of marijuana use, but parents' religious involvement, self-identification as a born-again Christian, and religious literalism did not have significant effects on the frequency of marijuana use. Roughly $13 \%$ of the effect of adolescent religious involvement was mediated by parental attachment, $11 \%$ by school attachment, $41 \%$ by delinquent peers, $19 \%$ by self-control, and only $2 \%$ by negative emotions. All of the indirect effects were statistically significant, except for negative emotions (for models using OLS regression, which we used for the supplemental analysis, the statistical significance of indirect effects can be determined in STATA using the command sgmediation).
} 
combined Wave 3 categories 5 and 6 (reasoning that these were equivalent to "once a week or more," as measured at Wave 1), categories 3 and 4 (equivalent to "once a month or more, but less than once a week" as measured at Wave 1), and categories 1 and 2 (equivalent to "less than once a month"). We performed similar operations for importance of religion and frequency of prayer, then we combined the three items into a single measure of religious involvement at Wave 3 , just as we did for Wave 1. After computing change in religious involvement from Wave 1 to 3 (a scale that ranged from 9 to -9 ), we created a set of dummy variables: increased religiosity, decreased religiosity, and no change from Wave 1 to Wave 3 . We also conducted the analysis with the religiosity change scale, and it showed the same pattern of results we present below.

Consistent with previous research (Uecker et al. 2007), as adolescents make the transition to young adulthood their religious involvement is more likely to decrease than increase. From Wave 1 to Wave 3, 47\% of adolescents decreased their religious involvement, 29\% increased their religious involvement, and $24 \%$ had the same religious involvement at Wave 1 and Wave 3. Adolescents with greater religious involvement increased, on average, 2.7 units (on a nine point scale) from Wave 1 to Wave 3. Adolescents with lower religious involvement decreased, on average, 2.9 units from Wave 1 to Wave 3. Therefore, although adolescents were more likely to decrease their religious involvement over time, many adolescents also significantly increased in religious involvement from adolescence to young adulthood.

Table 3 shows the results of models that include the change in religious involvement variables. "No change" in religious involvement is the omitted category.

Consistent with the results we report in Table 1, adolescents with high religious involvement, measured at Wave 1, are significantly more likely to never use marijuana than to persistently use marijuana. In contrast, adolescents who decreased their religious involvement over time, compared to adolescents with stable religious involvement, are significantly more likely to initiate marijuana use and to persistently use marijuana than they are to never use. An increase in religious involvement over time, however, did not have a significant effect on marijuana use patterns. Therefore, it appears that adolescents who decrease their religious involvement are more likely to initiate marijuana use, and to persistently use marijuana over time, but an increase in religiosity brings no additional protection from marijuana use.

The results from the analysis of change in adolescent religious involvement also suggests that religious youth, measured at Wave 1, are more likely to never use marijuana than to desist from marijuana use (Table 3, lower panel). In contrast, compared to adolescents with stable religious involvement, adolescents who decrease their religious involvement over time are more likely to desist from marijuana use than to never use marijuana. Obviously, in order to desist from marijuana use people must first use marijuana. As mentioned previously, adolescents who decrease their religious involvement over time are more likely to initiate marijuana use, and to persistently use marijuana, than to never use marijuana. Therefore, since adolescents who decrease in religiosity are more likely to initiate marijuana use, rather than never using, they are also more likely to desist than to never use. In addition, the results show that earlier (Wave 1) adolescent religious involvement again exhibits persistent effects on behavior in early adulthood.

Similar to the results reported in Table 1 and 2, when change in religious involvement is included in the models, parents' religious involvement and identifying as a born again Christian are not significantly related to marijuana use patterns. In contrast to previous results, however, when change in religious involvement is included in the models religious literalism does not have an effect on patterns of marijuana use. Many of the denominational differences noted 
TABLE 3

Multinomial Logistic Regression for Initial Use and Desistence of Marijuana Including Change in Religious Involvement (Standard Errors) (Theoretical Predictors and Controls Included but not Shown)

\begin{tabular}{|c|c|c|c|}
\hline & $\begin{array}{c}\text { Never use } \\
\text { (contrast) vs. } \\
\text { initiation }\end{array}$ & $\begin{array}{l}\text { Never use } \\
\text { (contrast) vs. } \\
\text { persistence }\end{array}$ & $\begin{array}{c}\text { Intermittent } \\
\text { (contrast) vs. } \\
\text { persistence }\end{array}$ \\
\hline Catholic & $.746(.435)$ & $1.016(.441)^{*}$ & $.270(.510)$ \\
\hline Evangelical Protestant & $.644(.549)$ & $.823(.530)$ & $.180(.706)$ \\
\hline Black Protestant & $1.396(.783)$ & $.977(.700)$ & $-.419(.937)$ \\
\hline Mainline Protestant & $.724(.550)$ & $1.018(.465)^{*}$ & $.294(.651)$ \\
\hline Other Affiliation & $.766(.522)$ & $1.121(.482)^{*}$ & $.355(.596)$ \\
\hline Religious Literalism & $.077(.059)$ & $.082(.063)$ & $.005(.068)$ \\
\hline Born Again Christian & $.053(.050)$ & $.013(.047)$ & $-.040(.060)$ \\
\hline Parent Religious Involvement & $-.029(.034)$ & $-.043(.030)$ & $-.013(.032)$ \\
\hline Adolescent Religious Involvement, Wave 1 & $-.079(.047)$ & $-.154(.044)^{* *}$ & $-.075(.050)$ \\
\hline Decrease in Religious Involvement, Waves $1-3^{\dagger}$ & $.522(.185)^{* *}$ & $.818(.226)^{* *}$ & $.296(.260)$ \\
\hline \multirow[t]{2}{*}{ Increase in Religious Involvement, Waves $1-3^{\dagger}$} & $.244(.266)$ & $.373(.232)$ & $.129(.251)$ \\
\hline & $\begin{array}{c}\text { Never use } \\
\text { (contrast) vs. } \\
\text { desistence }\end{array}$ & $\begin{array}{l}\text { Intermittent } \\
\text { (contrast) vs. } \\
\text { desistence }\end{array}$ & $\begin{array}{c}\text { Persistence } \\
\text { (contrast) vs. } \\
\text { desistence }\end{array}$ \\
\hline Catholic & $.283(.277)$ & $-.463(.420)$ & $-.733(.383)$ \\
\hline Evangelical Protestant & $.166(.351)$ & $-.478(.509)$ & $-.657(.513)$ \\
\hline Black Protestant & $.255(.411)$ & $-1.141(.801)$ & $-.722(.664)$ \\
\hline Mainline Protestant & $.062(.350)$ & $-.663(.525)$ & $-.957(.469)^{*}$ \\
\hline Other Affiliation & $.260(.308)$ & $-.506(.502)$ & $-.861(.446)$ \\
\hline Religious Literalism & $.012(.036)$ & $-.066(.064)$ & $-.071(.060)$ \\
\hline Born Again Christian & $-.016(.032)$ & $-.069(.051)$ & $-.029(.049)$ \\
\hline Parent Religious Involvement & $-.011(.022)$ & $.018(.033)$ & $.032(.027)$ \\
\hline Adolescent Religious Involvement, Wave 1 & $-.081(.029)^{* *}$ & $-.003(.042)$ & $.073(.040)$ \\
\hline Decrease in Religious Involvement, Waves $1-3^{\dagger}$ & $.458(.101)^{* *}$ & $-.064(.191)$ & $-.360(.228)$ \\
\hline Increase in Religious Involvement, Waves $1-3^{\dagger}$ & $.166(.131)$ & $-.078(.244)$ & $-.207(.219)$ \\
\hline
\end{tabular}

${ }^{*} p<.05 ;{ }^{* *} p<.01$.

${ }^{\dagger}$ No change in religiosity is the omitted category.

earlier, especially for never use versus initiation and persistence versus desistence, are also not significant. For example, when adolescents' religious involvement is not included, compared to adolescents with no religious affiliation, Catholics, mainline Protestants, and adolescents with other affiliations are all more likely to initiate marijuana use than to never use (see Table 1). In contrast, when change in adolescent religious involvement is considered, there are no significant denominational differences when initiation is compared to never using marijuana.

\section{Supplemental Analyses}

To check the robustness of our findings and to further elaborate our findings, we conducted several supplemental analyses (results available on request). First, we also examined changes 
in religiosity on changes in the frequency of marijuana use. We found that change in adolescent religious involvement from Wave 1 to Wave 3 had a significant effect on changes in the frequency of marijuana use from Wave 1 to Wave 3. The pattern of results is similar to the results for change in religiosity on initiation and persistence (Table 3). Adolescents who decrease in religiosity over time are significantly more likely to increase their frequency of marijuana use, compared to adolescents who do not change their religious involvement. On the other hand, compared to adolescents who are religiously stable, an increase in religiosity does not have a significant effect on change in the frequency of marijuana use. Also, as with the analyses above, the effects of religiosity on frequency were only partially mediated by peers, bonds, self control, and strain.

We also replicated our main analyses of marijuana use for alcohol use, and examined the effect of changes in religiosity on changes in the frequency of alcohol use. Note that the dynamics of alcohol use and alcohol use's legal and normative meaning change with age. Not surprisingly, people rarely desist from alcohol use. That is, since alcohol is legal (once you reach age 21) people tend to not desist from using alcohol once they get into their $20 \mathrm{~s}$ and $30 \mathrm{~s}$, when drinking is legal and in many contexts normatively accepted.

Regarding initiation and desistence, the results for alcohol use are fairly comparable to the results for marijuana use. That is, more religious youth are less likely to ever use alcohol even into early adulthood (and relatively little of this effect is mediated by the other predictors in the model). Religion, however, does not significantly predict desistence from alcohol use. One difference between marijuana and alcohol is the effect of parent's religiosity. Parent's religiosity has an effect for alcohol, but not marijuana. When their parents are more religious, youth are more likely to never use alcohol. Parent's religiosity does not predict alcohol desistence, however.

The results for change in the frequency of alcohol use are the same as the results for change in the frequency of marijuana use. Adolescents who decrease in religiosity from Wave 1 to Wave 3 are significantly more likely to increase their frequency of alcohol use, relative to adolescents who are religiously stable. On the other hand, an increase in religiosity is unrelated to changes in the frequency of alcohol use. Therefore, it appears that "losing your religion" contributes to an increase in substance use, but an increase in religion has no effect on the frequency of substance use.

\section{CONCLUSIONS}

Our results show that more religiously involved youth were less likely to ever use marijuana than those less religious, regardless of denomination. Also, controlling for denominational affiliation, adolescents who believe in a literal interpretation of religious scriptures are more likely to never use marijuana than to persist, and they are also more likely to desist than persist. However, identifying as a born again Christian and parental religious involvement did not significantly differentiate youth in their marijuana use. Thus, it appears that religious literalism is more predictive of marijuana use patterns than alternative measures of religious conservatism, such as identification as a born again Christian or membership in an evangelical Protestant tradition. Catholics and mainline Protestants were more likely than adolescents with no religious affiliation to initiate marijuana use or to be persistent marijuana users, rather than non-users. In addition, Catholics were more likely than adolescents with no religious affiliation to be persistent marijuana users. 
The analysis of change in adolescent religious involvement suggests that adolescents who decrease their religious involvement over time, compared to adolescents who are stable in their religious involvement, are significantly more likely to initiate marijuana use and to persistently use marijuana than to never use marijuana. In contrast, an increase in religious involvement over time did not have a significant effect on marijuana use patterns. Therefore, when it comes to changes in religiosity, it appears that only a decline in religious involvement predicts patterns of marijuana use. Given changes in the way adolescent religious involvement is measured over time, however, these results must be viewed with caution.

The analysis of change in adolescent religious involvement also helps to clarify the relationship between religious denomination and marijuana use. When change in religious involvement is not included in the model, there are many denominational differences in patterns of marijuana use, especially for initiation versus never use and persistence versus desistence. When change in religious involvement is included in the analysis, most of the significant effects for religious denomination are eliminated. This suggests that denominational differences in patterns of marijuana use could be the result of differences in how adolescents from these denominations change their religious involvement over time. That is, if a decrease in religious involvement predicts the initiation and persistent use of marijuana, and Catholics and mainline Protestants are more likely to decrease in religious involvement over time, then we would expect Catholics and mainline Protestants to be more likely to initiate marijuana use and to persistently use marijuana. Previous research on changes in religious involvement by denomination is consistent with this argument. According to Uecker et al. (2007), Catholics and mainline Protestants are more likely to decrease their religious service attendance over time than evangelical Protestants and black Protestants. Catholics and mainline Protestants are also more likely to decline in importance of religion, although the differences are not as large.

Change in religious involvement also eliminates the effect for religious literalism on patterns of marijuana use. Since evangelical Protestants are more likely to believe in a literal interpretation of sacred scriptures, and evangelical Protestants are less likely to decline in religious involvement over time, we would also expect adolescents who believe in a literal interpretation of sacred scriptures to be less likely to decrease their religious involvement over time. Therefore, the effect of religious literalism on patterns of marijuana use may also be explained by differences in how adolescents who believe in a literal interpretation of sacred scriptures change their religious involvement over time compared to those who do not believe in a literal interpretation of sacred scriptures.

The analysis of intervening mechanisms shows roughly a third of the effect of religious involvement on adolescents' patterns of marijuana use was mediated by social bonds, associating with delinquent peers, and self control. Furthermore, the pattern was roughly the same for never use versus initiation and never use versus persistence, although more of the effect of adolescent religious involvement on never use versus persistence was mediated by social bonding, social learning, and self control than never use versus initiation ( $27 \%$ versus $41 \%$, respectively). Similar to adolescent religious involvement, the analysis of intervening mechanisms suggested the effect of religious literalism on never use versus persistent use of marijuana was mediated primarily by social bonding, delinquent peers, and self control $(16 \%)$, although a small percentage of the effect of religious literalism was also mediated by negative emotions. Thus, as we hypothesized, part of adolescent religiosity's effects on marijuana use occur primarily because religiosity is associated with increased attachment to parents, greater self control, and fewer 
associations with delinquent peers. Thus, religiosity appears to work in tandem with as well as to influence key predictors of delinquency derived from social bonding, social learning, and self control theories.

One key limitation of our analysis is that we could not examine the effects of changes in theoretically relevant predictors of delinquency from earlier adolescence to early adulthood due to the lack of comparable measures across survey waves. Thus, it is important to remember that our findings regarding the effects of non-religious theoretical predictors of delinquency are specific to those variables' measurement in earlier adolescence. Notably, we do find enduring effects of earlier adolescent social bonds, peer relations, and self control on later marijuana use, suggesting that adolescent controls, bonds, and relationships shape behavior in important ways in early adulthood. However, future research that utilized data on change in religious involvement as well as change in important criminological predictors would make a substantial contribution to our understanding of delinquency, including marijuana use, across the early life course.

Finally, we expected that non-religious predictors from key criminological theories would not fully mediate the effects of religiosity, and they do not. About two thirds of religiosity's effects on patterns of marijuana use, particularly in discouraging initiation, is not mediated by the theoretically relevant predictors we included, or by controls. This is consistent with many previous findings in the literature we reviewed earlier. The finding that much of the effects of religiosity are unmediated and not attributable to secular factors has significance beyond the issue of marijuana use or delinquency. These findings thus support the argument of Pargament et al. (2005; see also Smith 2003) that the effects of religion on behavior are unique in that they are not wholly attributable to non-religious social or psychological factors.

\section{REFERENCES}

Agnew, Robert. 2006. Pressured into Crime: An Overview of General Strain Theory. Los Angeles, CA: Roxbury.

Akers, Ronald L. 1998. Social Learning and Social Structure: A General Theory of Crime and Deviance. Boston: Northeastern University Press.

Aziz, Shagufta and Ghazala Rehman. 1996. "Self Control and Tolerance Among Low and High Religious Groups." Journal of Personality and Clinical Studies 12:83-85.

Baier, Colin J. and Bradley R. E. Wright. 2001. "If You Love Me, Keep My Commandments: A Meta-Analysis of the Effect of Religion on Crime." Journal of Research in Crime and Delinquency 38:3-21.

Bearman, Peter S., Jo Jones, and J. Richard Udry. 1997. The National Longitudinal Study of Adolescent Health: Research Design. University of North Carolina at Chapel Hill: Carolina Population Center.

Benda, Brent B. 1997. "An Examination of a Reciprocal Relationship between Religiosity and Different Forms of Delinquency within a Theoretical Model." Journal of Research in Crime and Delinquency 34:163-186.

Benda, Brent B. and Robert Flynn Corwyn. 1997. "Religion and Delinquency: The Relationship after Considering Family and Peer Influences." Journal for the Scientific Study of Religion 36:81-92.

Burkett, Stephen R. and Bruce O. Warren. 1987. "Religiosity, Peer Associations, and Adolescent Marijuana Use: A Panel Study of Underlying Causal Structures.' Criminology 25:109-131.

Burkett, Stephen R. and M. White. 1974. "Hellfire and Delinquency: Another Look." Journal for the Scientific Study of Religion 16:263-274.

Chantala, Kim, William D. Kalsbeek, and Eugenio, Andraca. 2004. Non-Response in Wave III of the Add Health Study. Carolina Population Center, University of North Carolina at Chapel Hill.

Chantala, Kim and Joyce Tabor. 1999. Strategies to Perform a Design-Based Analysis Using the Add Health Data. Carolina Population Center, University of North Carolina at Chapel Hill.

Chitwood, Dale, Michael Weiss, and Carl Leukefeld. 2008. “A Systematic Review of Recent Literature on Religiosity and Substance Abuse.” Journal of Drug Issues 38:653-688. 
Chu, Doris C. 2007. "Religiosity and Desistence from Drug Use.” Criminal Justice and Behavior 34:661-679.

Cochran, John K. and Ronald L. Akers. 1989. "Beyond Hellfire: The Variable Effects of Religiosity on Adolescent Alcohol and Marijuana Use." Journal of Research in Crime and Delinquency 26:198-225.

Desmond, Scott, Jeffery Ulmer, and Christopher Bader. 2007. "Religion, Self Control, and Adolescent Delinquency." Presented at Religious Practice and Civic Life: What the Research Says, the Heritage Foundation, Child Trends, and the Baylor Institute for Studies of Religion. Washington, DC. Available at http://www.heritage.org/Research/ Features/Religion/ConfPapers.cfm

Elifson, Kirk W., David M. Petersen, and C. Kirk Hadaway. 1983. "Religiosity and Delinquency: A Contextual Analysis." Criminology 21:505-527.

Geyer, Anne and Roy F. Baumeister. 2005. "Religion, Morality, and Self Control.” Pp. 412-432 in Handbook of the Psychology of Religion and Spirituality, edited by R. F. Paloutzian and C. L. Park. New York: Guilford Press.

Giordano, Peggy C., Stephen A. Cernkovich, and Jennifer L. Rudolph. 2002. "Gender, Crime, and Desistence: Toward a Theory of Cognitive Transformation." American Journal of Sociology 107:990-1064.

Giordano, Peggy C., Monica A. Longmore, Ryan D. Schroeder, and Patrick M. Seffrin. 2008. “A Life Course Perspective on Spirituality and Desistence from Crime.' Criminology 46:99-131.

Glanville, Jennifer, David Sikkink, and Edwin Hernandez. 2008. "Religious Involvement and Educational Outcomes: The Role of Social Capital and Extracurricular Participation.'” The Sociological Quarterly 49:105-138.

Hay, Carter and Walter Forrest. 2006. “The Development of Self Control: Examining Self Control Theory's Stability Thesis." Criminology 44:739-774.

Hirschi, Travis. 1969. Causes of Delinquency. Berkeley, CA: Free Press.

Jang, Sung Joon and Byron R. Johnson. 2003. "Strain, Negative Emotions, and Deviant Coping among African Americans: A Test of General Strain Theory." Journal of Quantitative Criminology 19:79-105.

- 2005. "Gender, Religiosity, and Reactions to Strain among African Americans." Sociological Quarterly 46: 323-358.

Jang, Sung Joon, Christopher D. Bader, and Byron R. Johnson. 2008. "The Cumulative Advantage of Religiosity in Preventing Drug Use." Journal of Drug Issues 38:771-798.

Johnson, Byron R., Spencer De Li, David Larson, and Michael E. McCullough. 2000. "Religion and Delinquency: A Systematic Review of the Literature." Journal of Contemporary Criminal Justice 16:32-52.

Johnson, Byron R., Sung Joon Jang, David B. Larson, and Spencer D. Li. 2001. "Does Adolescent Religious Commitment Matter? A Reexamination of the Effects of Religiosity on Delinquency." Journal of Research in Crime and Delinquency 38:22-44.

Koenig, Harold G., Michael E. McCullough, and David B. Larson. 2001. Handbook of Religion and Health. New York: Oxford University Press.

Lattimore, T. Lorraine, Charles Tittle, and Harold Grasmick. 2006. "Childrearing, Self Control, and Crime: Additional Evidence." Sociological Inquiry 76:343-371.

Long, Scott J. 1997. Regression Models for Categorical and Limited Dependent Variables. Thousand Oaks, CA: Sage.

Muraven, Mark and Roy F. Baumeister. 2000. "Self Regulation and Depletion of Limited Resources: Does Self Control Resemble a Muscle?' Psychological Bulletin 126:247-259.

Pargament, Kenneth I. 1997. The Psychology of Religion and Coping: Theory, Research, Practice. New York: The Guilford Press.

. 2008. "The Sacred Character of Community Life." American Journal of Community Psychology 41:22-34.

Pargament, Kenneth, Gina Magyar-Russell, and Nichole Murray-Swank. 2005. "The Sacred and the Search for Significance: Religion as a Unique Process.' Journal of Social Issues 61:665-687.

Perrone, Dina, Christopher J. Sullivan, Travis C. Pratt, and Satenik Margaryan. 2004. "Parental Efficacy, Self-Control, and Delinquency: A Test of a General Theory of Crime on a Nationally Representative Sample of Youth." International Journal of Offender Therapy and Comparative Criminology 48:298-312.

Petts, Richard. 2009. “Family and Religious Characteristics' Influence on Delinquency Trajectories from Adolescence to Young Adulthood." American Sociological Review 74(3):465-483.

Regnerus, Mark. 2006. “Adolescent Delinquency." Pp. 265-282 in Handbook of Religion and Social Institutions, edited by H. R. Ebaugh. New York: Springer.

Sampson, Robert J. and John H. Laub. 1993. Crime in the Making: Pathways and Turning Points through the Life. Cambridge, MA: Harvard University Press. 
Schroeder, Ryan and John F. Frana. 2009. "Spirituality and Religion, Emotional Coping, and Criminal Desistence: A Qualitative Study of Men Undergoing Change.' Sociological Spectrum 29(6):718-741.

Smith, Christian. 2003. Moral, Believing Animals: Human Personhood and Culture. New York: Oxford University Press.

Steensland, Brian, Jerry Z. Park, Mark D. Regnerus, Lynn D. Robinson, W. Bradford Wilcox, and Robert Woodberry. 2000. "The Measure of American Religion: Toward Improving the State of the Art." Social Forces 79:291-318.

Uecker, Jeremy, Mark Regnerus, and Margaret Vaaler. 2007. "Losing My Religion: The Social Sources of Religious Decline in Early Adulthood.' Social Forces 85:1667-1692.

Vaisey, Stephen. 2009. “Motivation and Justification: A Dual Process Model of Culture in Action.' American Journal of Sociology 114:1675-1716.

Wallace, John M., Ryoko Yamaguchi, Jerald Bachman, Patrick O’Malley, John Schulenberg, and Lloyd Johnston. 2007. "Religiosity and Adolescent Substance Use: The Role of Individual and Contextual Influences.' Social Problems 54:308-327.

Warr, Mark. 2002. Companions in Crime: The Social Aspects of Criminal Conduct. Cambridge, UK: Cambridge University Press.

Welch, Michael, Charles Tittle, and Harold Grasmick. 2006. "Christian Religiosity, Self Control, and Social Conformity.' Social Forces 84:1605-1623.

JEFFERY T. ULMER is Associate Professor of Sociology and Crime, Law, and Justice. His published research has focused on courts and sentencing, criminological theory, race, ethnicity, and violence, religion and crime, symbolic interactionism, criminal enterprise, and the integration of qualitative and quantitative methods. He is the author of Social Worlds of Sentencing: Court Communities Under Sentencing Guidelines (1997, State University of New York Press), and coauthor (with Darrell Steffensmeier) of Confessions of a Dying Thief: Understanding Criminal Careers and Illegal Enterprise (2005, Aldine-Transaction), which won the 2006 Hindelang Award from the American Society of Criminology. His newest book (with John Kramer), Sentencing Guidelines: Lessons from Pennsylvania, was published in 2009 by Lynne Rienner Publishers.

SCOTT A. DESMONDis a Visiting Assistant Professor in the School of Public and Enviornmental Affaris at Indiana University Purde University-Indianapolis. Although his research focuses primarily on adolescent religious development, and how adolescent religiosity influences juvenile delinquency, he also studies how neighborhood characteristics and self-control contribute to crime, delinquency, and substance use.

SUNG JOON JANG is Associate Professor of Sociology and Research Fellow in the Program on Prosocial Behavior of the Institute for Studies of Religion at Baylor University. His research focuses on the effects of family, school, peers, religion, and community on crime and deviance. He is a co-principal investigator of a project on character development and spirituality among Boy Scouts and Eagle Scouts.

BYRON R. JOHNSON is Distinguished Professor of the Social Sciences and Director of the Institute for Studies of Religion, both at Baylor University. He has published extensively on the role of religion in preventing delinquency and fostering prosocial behavior. 